УДК 902/552

https://doi.org/10.24852/2587-6112.2021.3.96.101

\title{
К ВОПРОСУ О РЕЖИМЕ ОБЖИГА ОБЩЕБОЛГАРСКОЙ КЕРАМИКИ ДОМОНГОЛЬСКОГО И РАННЕОРДЫНСКОГО ВРЕМЕНИ (ПО МАТЕРИАЛАМ Р.СХСІІ БОЛГАРСКОГО ГОРОДИЩА)
}

\author{
(C) 2021 г. А.А. Куклина, О.Ю. Андрушкевич
}

На настоящий момент температурный режим обжига общеболгарской керамики является нерешенным вопросом. Долгое время обжиг массовой гончарной керамики оценивался исключительно в рамках субъективных понятий «плохой»/«хороший». В рамках проведенного исследования серии петрографических шлифов общеболгарской керамики Болгарского городища были получены некоторые результаты, дающие представление о верхней границе обжиговых температур. Сопоставляя эти данные со сведениями о конструкциях гончарных горнов Болгара домонгольского и раннезолотоордынского времени, авторами статьи выдвинуто предположение о характере обжига массовой гончарной керамики местного производства в X - начале XIV вв.

Ключевые слова: археология, петрография, средневековье, Болгарское городище, керамика, гончарное производство, обжиг.

\section{TO THE DISCUSSION OF THE FIRING METHOD OF COMMON BOLGAR CERAMICS IN THE PRE-MONGOL AND EARLY GOLDEN HORDE PERIODS (ON THE BASIS OF EXCAVATION CXCII AT BOLGAR FORTIFIED SETTLEMENT)}

\author{
A.A. Kuklina, O.Yu. Andrushkevich
}

The firing method of common Bolgar ceramics remains an unsolved question. For a long time, the firing of common wheel pottery was only evaluated in subjective terms "bad" and "good". In the framework of the study of a series of petrographic slice of common Bolgar ceramics from the Bolgar fortified settlement, results were obtained, which shed light on the upper limit of the firing temperatures. By comparing this data with construction details of Bolgar kilns built in the Pre-Mongol and Early Golden Horde periods, an assumption was made about the firing method of local wheel pottery in the $10^{\text {th }}-$ early $14^{\text {th }} \mathrm{cc}$.

Keywords: archaeology, petrography, Middle ages, Bolgar fortified settlement, ceramic, pottery, firing.

Общеболгарская, или керамика I группы по классификации Т.А. Хлебниковой (Хлебникова, 1984), является массовой на территории Болгарского городища и многих других памятников. Ее содержание в слоях и заполнении сооружений достигает $90 \%$ керамического комплекса домонгольского и золотоордынского времени (Кокорина, 2002, с. 49, 114). Исследованию этого материала посвящены труды А.П. Смирнова, О.С. Хованской, Т.А. Хлебниковой, И.Н. Васильевой, Н.А. Кокориной. Таким образом, на настоящий момент вопросы морфологии и типологии общеболгарской керамики, а также некоторые технологические аспекты, такие как отбор сырья и его подготовка, конструирование сосудов, довольно хорошо освещены. Тем не менее существует ряд вопросов, которые требуют более детального изучения. Одной из таких проблем является уточнение характеристик обжига данной керамики.

Особенности обжига болгарской керамики довольно подробно были описаны О.С. Хован- ской. По ее мнению, в домонгольском периоде существования Болгара были распространены традиции обжига в домашних печах как в окислительном, так и в восстановительном пламени. Разница в качестве обжига объясняется различиями в конструкциях самих печей. Самое высокое качество керамики связано с горновым обжигом (Хованская, 1954, с. 345). Многие исследователи отмечали преобладание керамики более слабого обжига (желтого и коричневого цветов) в домонгольских слоях Болгара в отличие от слоев золотоордынского времени, где цвет посуды преимущественно красный, что является показателем высокой температуры обжига (Калинин, 1950, с. 43; Калинин, Халиков, 1954, с. 71; Смирнов, 1952, c. 21).

Позже И.Н. Васильева, проводя технико-технологический анализ групп керамики, выделенных Т.А. Хлебниковой, обратила внимание, что в домонгольское время традиция обжига керамики в восстановительном пламени стала гораздо менее распространена 


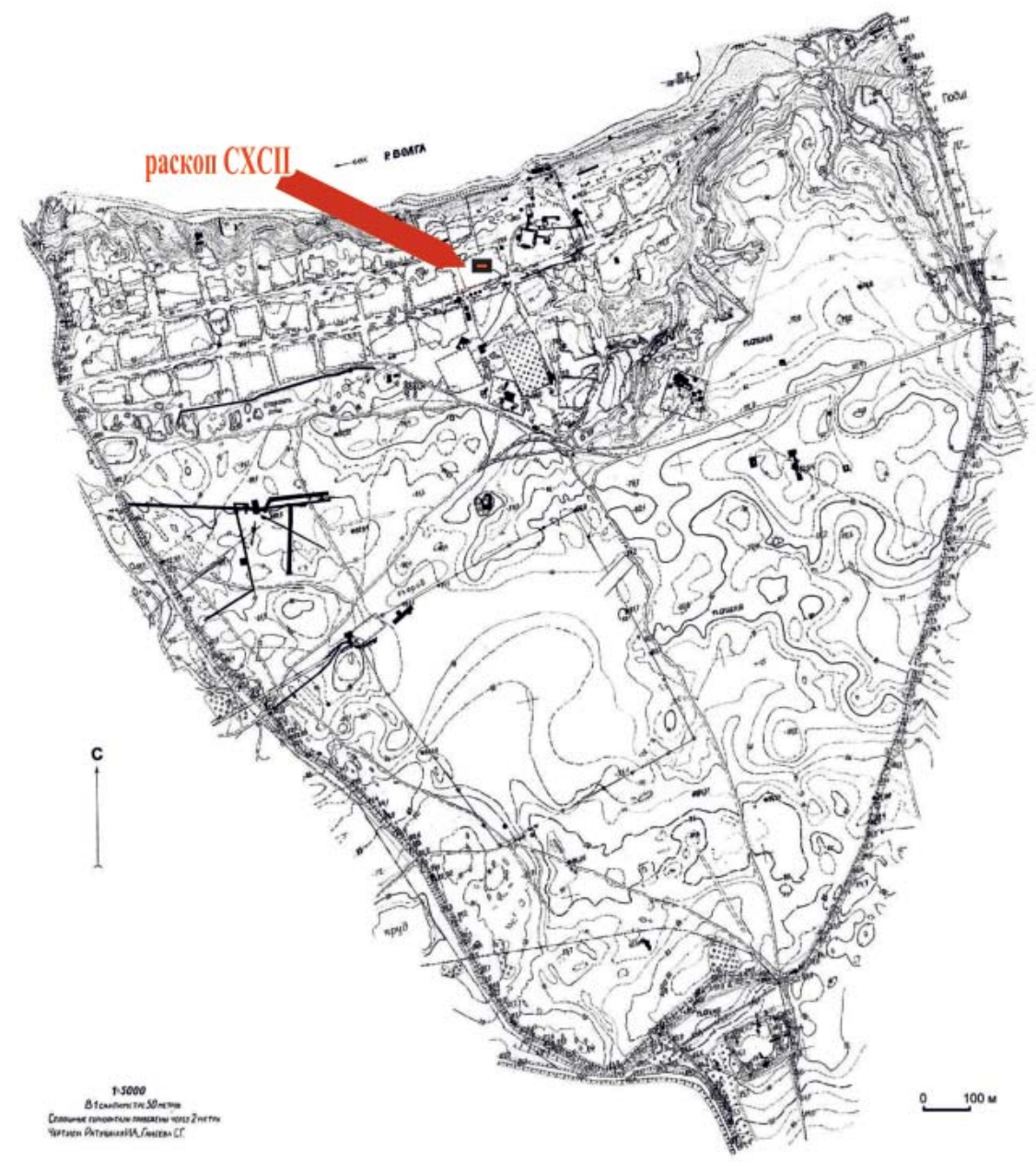

Рис. 1. Топографический план Болгарского городища с указанием расположения р. СХCII (по Бадеев, Коваль, 2019)

Fig. 1. Topographic plan of Bolgar fortified settlement indicating the location of excavation CXCII (after Badeev, Koval, 2019)

на памятниках Волжской Булгарии по сравнению с раннеболгарским периодом. Развитие традиции окислительного обжига связывается ею с появлением двухкамерных горнов (Васильева, 1988, с. 144). В частности, для домонгольского Болгара характерна конструкция горнов с восходящим пламенем, что подразумевает довольно существенную потерю тепла при обжиге (Васильева, 1988, с. 138). Следовательно, в домонгольское время температура обжига ремесленной керамики действительно могла быть ниже, чем в позднезолотоордынское, когда усиливается среднеазиатское влияние на гончарное дело в Болгаре и размеры горнов увеличиваются. Стоит также отметить, что конструкции горнов из раннеордынского слоя Болгарского городища такие же, как в домонгольском (Васильева, 1988, с. 144-146).

Определение температуры обжига древней и средневековой керамики является непростой задачей. Одним из путей ее решения является метод экспериментального обжига в муфель- ной печи, разработанный Е.В. Волковой и Ю.Б. Цетлиным (Волкова, Цетлин, 2016, с. 254-265). Другой способ представляет собой проведение петрографического анализа.

При горновом обжиге происходит нагревание керамических изделий до определенной температуры и выдерживание в течение некоторого времени. Равномерный коричневый цвет черепка готового сосуда говорит о довольно продолжительном выдерживании при температуре, достаточной для полного окисления соединений железа, входящих в состав глины (Глушков, 1996, с. 81). Черепок, имеющий прослойку серого цвета, является показателем того, что изделие подвергалось короткой выдержке в горне и довольно быстрому остыванию (Цетлин, 2012, с. 117). Обжиг может быть низкотемпературным - от 450 до 650 градусов C - или высокотемпературным - выше 650-700 градусов (Цетлин, 2012, с. 117-118). При этом температуры каления глины (когда она утрачивает свою пластичность) начинаются от 500-550 граду- 

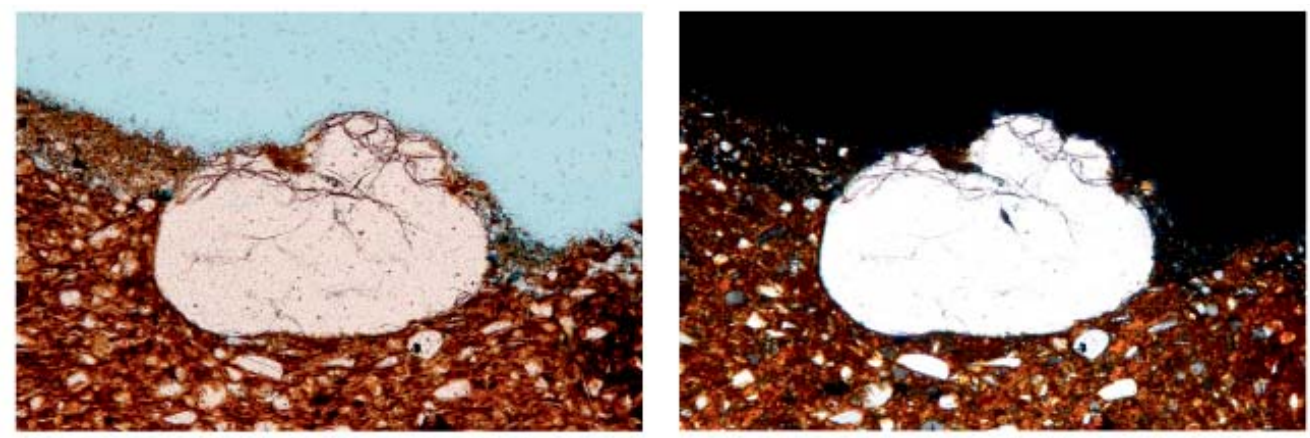

0

$1 \mathrm{Mm}$

Рис. 2. Зерно кварца в приповерхностном слое фрагменте керамики со следами температурного воздействия (система микротрещин и корродированная каёмка). Образец подгруппы 4л (р. CXCII)

Fig. 2. Quartz grain in the near-surface layer of a ceramic fragment with traces of temperature exposure (a system of microcracks and a corroded border). Sample of subgroup 41 (ex. CXCII)
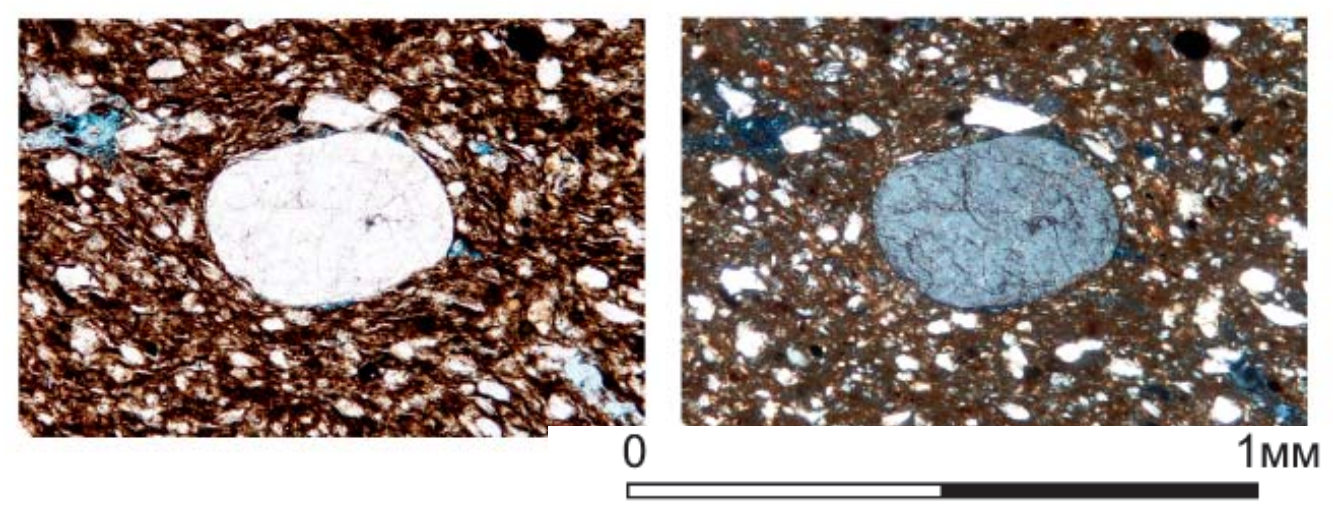

Рис. 3. Зерно кварца внутри фрагмента керамики со следами температурного воздействия (начало развития системы микротрещин). Образец подгруппы 2т (р. CXCII)

Fig. 3. Quartz grain inside a ceramic fragment with traces of temperature exposure (the beginning of the development of a system of microcracks). Sample of subgroup $2 \mathrm{t}$ (ex. CXCII)

сов. Здесь уже можно наблюдать эффект так называемого красного свечения (Цетлин, 2012, c. 116).

Поскольку общеболгарская керамика в основной своей массе имеет красный и коричневый цвет черепка, можно утверждать, что она подвергалась нагреву не ниже 500 градусов Цельсия. Некоторое представление о верхней границе температурного режима обжига этой керамики может дать петрография. Наиболее пригодным компонентом для оценки температуры обжига является кварцевый песок, поскольку известно, что при температуре 573-575 градусов Цельсия начинается процесс перекристаллизации, когда $\alpha$-кварц переходит в $\beta$-кварц (Бетехтин, 1951, c. 355), что сопровождается образованием трещин (Глушков, 1996, с. 78).

Для исследования были отобраны образцы общеболгарской керамики разных подгрупп $1 \mathrm{r,} \mathrm{2т,} \mathrm{3т,} \mathrm{4т,} \mathrm{5т,} \mathrm{1л,} \mathrm{2л,} \mathrm{3л,} \mathrm{4л,} \mathrm{5л,} \mathrm{6л,} \mathrm{7л} \mathrm{(Кукли-}$ на, 2018, 2020) - количеством 126 штук. Отбор керамики был произведен из сооружений домонгольского (X - нач. XIII вв.) и раннезолотоордынского времени (1236 г. - нач. XIV в.) с раскопа CXCII (рис. 1). Выбранные подгруппы можно условно разделить на две части: с полной прокаленностью черепка (1т, 4т, 1л, 2л, 3л, 6л) и с неполной (2т, 3т, 5т, 4л, 5л, 7л).

При изучении шлифов особое внимание уделялось поиску доказательств и оценке величин температурного воздействия на исследуемые образцы.

В исследованной серии несколько образцов заслуживают более пристального внимания: образцы подгруппы 3л № 2722 (фрагмент сосуда), подгруппы 5л № 26.1 (фрагмент корчаги), подгруппы 1т № 8.1 (фрагмент широкогорлого кувшина), подгруппы 2т № 27.3 (фрагмент миски), 3т подгруппы № 2535 (фрагмент сосуда), подгруппы 4т № 17.2 (фрагмент горшка) и фрагмент керамики восстановительного обжига № 9.2 (фрагмент сосуда). По мнению авторов, именно в этих фрагментах уверен- 

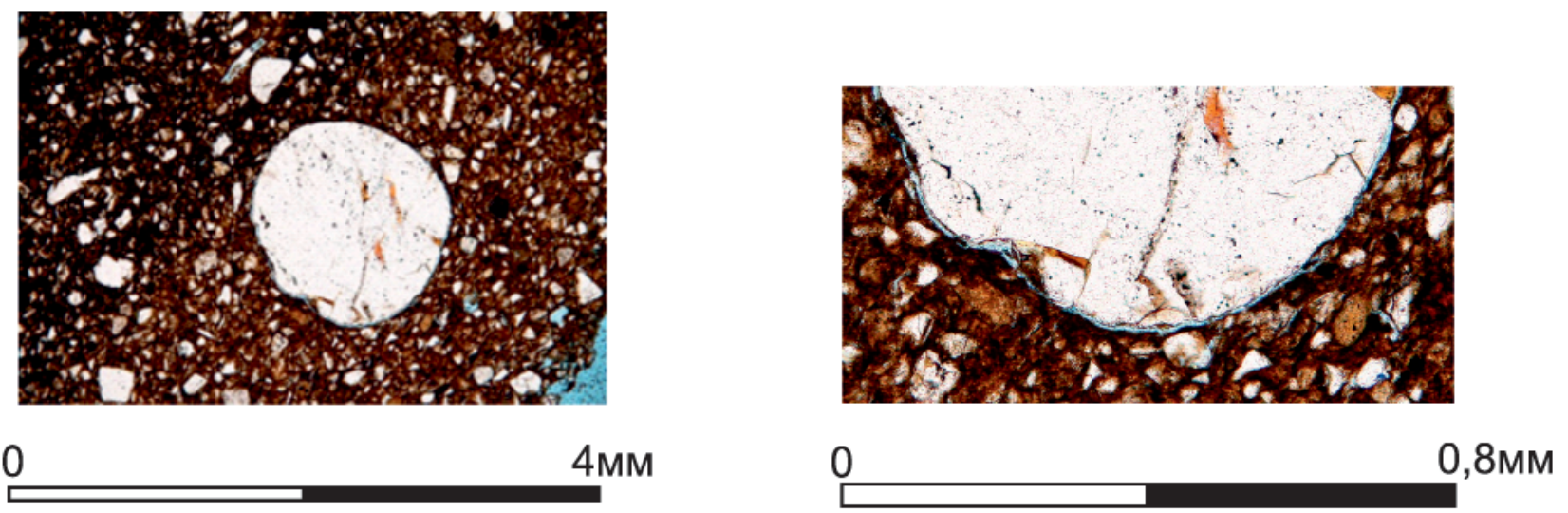

Рис. 4. Крупное зерно кварца с окраской микротрещин гидроокислами железа.

Образец подгруппы 3л (р. СXCII)

Fig. 4. Coarse quartz grain with microcrack staining with iron hydroxides. Sample of subgroup 31 (ex. CXCII)

но диагностируются минералы, по которым можно приблизительно восстановить температурные режимы обжига.

В шлифах всех перечисленных образцов наблюдается некоторое количество раздробленных (трещиноватых) зёрен кварца (рис. 2, 3). Микротрещины в кварцевых зёрнах явление вполне обычное, широко распространённое в природе. Но, как правило, природные трещины редко бывают чистыми, гораздо чаще наблюдается заполнение их какой-либо субстанцией: окраска гидроокислами железа, тонкая вторичная минерализация, присутствие пелитовой составляющей и т. п. (Бетехтин, 1951, с. 361). В качестве примера можно привести рис. 4, на котором отчётливо видна окраска микротрещины гидроокислами железа.

Интересно, что в образцах подгрупп 1т № 8.1, 3т № 2535 и 4т № 17.2 трещины исключительно малы и отчётливо видны только на больших (×40) увеличениях. Можно предположить, что в данном случае речь идёт о самом начале процесса перекристаллизации (температура немного выше $575^{\circ} \mathrm{C}$ ) или о незначительном времени воздействия более высоких температур на гончарное изделие.

В образцах же подгрупп 3л № 2722, 2т № 27.3 и восстановительного обжига №9.2 трещины видны более отчётливо, соответственно, данные образцы могли подвергаться воздействию либо более высоких температур, либо более продолжительному по времени режиму обжига.

Стоит обратить особое внимание на образец подгруппы 4л № 2579 (рис. 2). Отчётливо видно в шлифе, что выходящее на поверхность керамики зерно кварца сильно раздроблено только в выступающей части, а та часть зерна, которая лежит внутри глинистой матрицы, остаётся целой. В данном случае нельзя делать однозначный вывод о температуре обжига в $575^{\circ} \mathrm{C}$. Вполне вероятно, что образование такой специфичной микротрещиноватости связано с резким охлаждением гончарного изделия (разрушение печи для обжига, попадание влаги и т. п.).

В шлифах остальных 119 образцов подобной трещиноватости в кварцевых зёрнах обнаружено не было. Всё это даёт основание осторожно предположить, что температуры обжига исследуемой керамики не превышали $575^{\circ} \mathrm{C}$.

Таким образом, учитывая конструктивные особенности горнов Болгара и результаты проведенного исследования общеболгарской керамики, можно говорить о том, что обжиг ремесленной керамики домонгольского и раннеордынского времени (X - нач. XIV вв.) мог быть низкотемпературным. Однако пока нельзя утверждать, что вся керамика этого времени обжигалась исключительно при низких температурах.

\section{ЛИТЕРАТУРА}

Бетехтин А.Г. Минералогия. М.: Госгеолиздат, 1950. 956 с

Бадеев Д.Ю., Коваль В.Ю. Отчет об археологических раскопках на Болгарском городище (раскоп СХСІІ) в 2018 году. М., 2019 / Архив ИА РАН.

Васильева И.Н. О технологии производства неполивной керамики Болгарского городища // Город Болгар: очерки ремесленной деятельности. / Отв.ред. Г.А.Федоров-Давыдов. М.: Наука, 1988. C. $103-148$. 
Волкова Е.В., Цетлин Ю.Б. О разработке методики определения температуры обжига древней керамики. // КСИА. 2016. Вып. 245. С. 254-264.

Глушков И.Г. Керамика как исторический источник. Новосибирск: Изд-во Института археологии и этнографии СО РАН, 1996. $328 \mathrm{c.}$

Калинин Н.Ф. Отчет о работах по западным районам ТАССР, 1950 г. / Архив ИА РАН, д. Р-1, №531

Калинин Н.Ф., Халиков А.Х. Итоги археологических экспедиций КФАН СССР по Татарии за 1945-1952 гг.// Труды ИЯЛИ. Казань: Татгосиздат, 1954. 126 с.

Кокорина Н.A. Керамика Волжской Булгарии второй половины XI - начала XV веков (к проблеме преемственности булгарской и булгаро-татарской культур). Казань: ИИ АН РТ, ИА РАН, 2002. 383 с.

Куклина A.A. Неполивная керамика Болгара с раскопов в юго-восточной части городища (по материалам раскопов CCXVI, CCXXI, CCXXIII 2016 г.) // Археология Евразийских степей. 2018. №5. C. $185-192$

Куклина А.А. Новые исследования общеболгарской керамики: историко-культурный подход // Поволжская археология. 2020. №2 (32). С. 228-237.

Смирнов А.П. Археологические исследования 1950 года в зоне строительства Куйбышевской ГЭС. // КСИИМК. Вып.44. М.: Изд-во АН СССР, 1952. С. 17-29.

Хлебникова T.A. Керамика памятников Волжской Болгарии. К вопросу об этнокультурном составе населения. М.: Наука, 1984. 241 с.

Хованская О.С. Гончарное дело города Болгара // МИА. № 42 / Отв. ред. А.П. Смирнов. М.: АН ССCР 1954. С. $340-368$.

Цетлин Ю.Б. Древняя керамика. Теория и методы историко-культурного подхода. М.: ИА РАН, 2012. $384 \mathrm{c}$.

\section{Информация об авторах:}

Куклина Анна Александровна, младший научный сотрудник, Институт археологии им. А.Х. Халикова АН РТ (г. Казань, Россия); kuklinanna@mail.ru

Андрушкевич Олег Юрьевич, заведующий Лабораторией, Казанский (Приволжский) федеральный университет (г. Казань, Россия); gemmaol@bk.ru

\section{REFERENCES}

Betekhin, A. G. 1950. Mineralogiia (Mineralogy). Moscow: "Gosgeolizdat” Publ. (in Russian).

Badeev, D. Yu., Koval, V. Yu. 2019. Otchet ob arkheologicheskikh raskopkakh na Bolgarskom gorodishche v 2018 g. Raskop CXCII (Report on Archaeological Activities at Bolgar Fortified Settlement in 2018. Excavation 192). Moscow. Archive of the Institute of Archaeology of the Russian Academy of Sciences (in Russian).

Vasil'eva, I. N. 1988. In Fedorov-Davydov, G. A. (ed.). Gorod Bolgar. Ocherki remeslennoi deiatel'nosti (Town of Bolgar. Essays on Handicrafts). Moscow: "Nauka" Publ., 103-148. (in Russian).

Volkova, E. V., Tsetlin, Yu. B. 2016. In Kratkie soobshcheniia Instituta arkheologii (Brief Communications of the Institute of Archaeology) 245. 254-264 (in Russian).

Glushkov, A. G. 1996. Keramika kak istoricheskii istochnik (Ceramics as a Historical Source). Novosibirsk: Institute of Archaeology and Ethnography of the Siberian Branch, Russian Academy of Sciences Publ. (in Russian).

Kalinin, N. F. 1950. Otchet o rabotakh po zapadnym raionam TASSR (Report on Activities in the Western Regions of the Tatar Autonomous Soviet Socialist Republic). Archive of the Institute of Archaeology of the Russian Academy of Sciences. R-1, dossier 531 (in Russian).

Kalinin, N. F., Khalikov,A. Kh. 1954. In Trudy Kazanskogo filiala Akademii nauk SSSR. Seriia istoricheskikh nauk (Proceedings of the Kazan Branch of the USSR Academy of Sciences. Historical Sciences Series). Kazan: "Tatknigoizdat" Publ. (in Russian).

Kokorina, N. A. 2002. Keramika Volzhskoi Bulgarii vtoroi poloviny XI-nachala XV vv.: K probleme preemstvennosti bulgarskoi i bulgaro-tatarskoi kul'tur (Ceramic Ware in Volga Bulgaria during the Second Half of the $11^{\text {th }}$-Beginning of the $15^{\text {th }}$ Centuries (on the Issue on Succession of the Bulgar and Bulgar-Tatar Cultures)). Kazan: Institute of History named after Shigabuddin Mardjani, Tatarstan Academy of Sciences; Russian Academy of Sciences, Institute of Archaeology (in Russian).

Kuklina, A. A. 2018. In Arkheologiia Evraziiskikh stepei (Archaeology of Eurasian Steppes) 5, 185-192 (in Russian). 
Kuklina, A. A. 2020 In Povolzhskaya arkheologiya (Volga River Region Archaeology) 32 (2), 228-237 (in Russian).

Smirnov, A. P. 1952. In Kratkie soobshcheniia Instituta istorii material'noi kul'tury (Brief Communications of the Institute for the History of Material Culture) 44. Moscow: Academy of Sciences of the USSR, 17-29 (in Russian).

Khlebnikova, T. A. 1984. Keramika pamiatnikov Volzhskoi Bolgarii: (K voprosu ob etnokul'turnom sostave naseleniia) (Ceramic Ware ft he Volga Bolgaria Sites. On the Issue of Ethnic and Cultural Composition of the Population). Moscow: "Nauka" Publ. (in Russian).

Khovanskaya, O. S. 1954. In Smirnov, A. P. (ed.). Materialy i issledovaniia po arkheologii SSSR (Materials and Research in the USSR Archaeology) 42. Moscow: Academy of Sciences of the USSR, 340-368 (in Russian).

Tsetlin, Yu. B. 2012. Drevniaia keramika. Teoriia i metody istoriko-kul'turnogo podkhoda (Ancient Ceramics. The Theory and Methods of Historical and Cultural Approach). Moscow: Institute of Archaeology of the Russian Academy of Sciences (in Russian).

\section{About the Authors:}

Kuklina Anna A. Institute of Archaeology named after A.Kh. Khalikov, Academy of Sciences of the Republic of Tatarstan. Butlerov St., 30, Kazan, 420012, Republic of Tatarstan, Russian Federation; kuklinanna@ mail.ru

Andrushkevich Oleg Yu. Kazan (Volga Region) Federal University. Kremlyovskaya str., 18, Kazan, 420008, Republic of Tatarstan, Russian Federation; gemmaol@bk.ru

Статья поступила в журнал 01.04.2021 г.

Статья принята к публикации 01.04.2021 г.

Авторы внесли равноценный вклад в работу. 